\title{
Enamel defects and tooth eruption disturbances in children with sickle cell anemia
}

Caroline Maria Igrejas LOPES(a) Marília Cabral CAVALCANTI(b) Ana Cláudia ALVES E LUNA ${ }^{(a)}$ Kátia Maria Gonçalves MARQUES(c) Maria José RODRIGUES ${ }^{(d)}$ Valdenice Aparecida DE MENEZES(d)

(a) Universidade de Pernambuco - UPE, School of Dentistry, Camaragibe, PE, Brazil.

(b) Universidade de São Paulo - USP, School of Dentistry, São Paulo, SP, Brazil.

(c) Universidade Federal de Pernambuco UFPE, School of Dentistry, Department of Clinical and Preventive Dentistry, Recife, PE, Brazil.

(d) Universidade de Pernambuco - UPE, School of Dentistry, Department of Pediatric Dentistry, Camaragibe, PE, Brazil.

Declaration of Interest: The authors certify that they have no commercial or associative interest that represents a conflict of interest in connection with the manuscript.

\section{Corresponding Author:}

Caroline Maria Igrejas Lopes

E-mail: carol_igrejas@hotmail.com

hitps://doi.org/10.1590/1807-3107bor-2018.vol32.0087

Submitted: October 25, 2017

Accepted for publication: June 27, 2018

Last revision: July 17, 2018
Abstract: Sickle cell anemia, a genetic disease caused by a mutation in the beta-globin gene, can present oral manifestations such as delayed tooth eruption and hypomineralized enamel and dentin. The aim of the present study was to evaluate the prevalence and severity of developmental defects of enamel (DDE) and delayed tooth eruption in children with sickle cell anemia. The sample comprised 56 male and female children with sickle cell anemia aged 6 to 12 years and treated at the Hematology and Hemotherapy Center of Pernambuco, Brazil. The data were collected according to the WHO criteria for DDE and tooth eruption. The prevalence of DDE was $58.2 \%$ and increased with age, affecting $43.8 \%$ of children aged 6 to 8 years and $66.7 \%$ of those aged 10 to 12 years ( $p>0.05$; Pearson's chi-square test). There was no significant association between DDE and sex; the most prevalent type of DDE was diffuse opacity (6.2\%). Tooth eruption was delayed in 18 children (32.1\%). The delay increased with age and was detected in $11.8 \%$ of children aged 6 to 8 years, in $20.0 \%$ of those aged 8 to 10 years and in $54.2 \%$ of those aged 10 to 12 years ( $<<0.05$; Pearson's chi-square test). Delayed tooth eruption was higher in males $(36.7 \%, \mathrm{p}>0.05)$. The prevalence of DDE was high, increased with age and was similar between sexes, while delayed eruption was higher in males and showed a significant association with age.

Keywords: Anemia, Sickle Cell; Tooth Abnormalities; Tooth Eruption.

\section{Introduction}

Hemoglobinopathies used to be highly region-specific with a predilection for African, Mediterranean, Middle Eastern, Southeast Asian and Indian subcontinental groups. However, because of widespread global migration, they affect at least $5.2 \%$ of the global population. Annually, there are over 332,000 affected conceptions or births, of which 275,000 are affected by sickle cell disorder requiring early diagnosis and prophylaxis. Most affected children born in high-income countries survive with a chronic disorder, while most of those born in low-income countries die before the age of 5 years, and hemoglobin disorders contribute the equivalent of $3.4 \%$ of mortality in children aged under 5 years worldwide or $6.4 \%$ in Africa. ${ }^{1}$ The major forms of hemoglobinopathies are often severe and their management is difficult and associated with a great psychosocial 
impact on patients and their families. ${ }^{2}$ In Brazil, sickle cell anemia is the most common hereditary monogenic disease, being considered endemic, reaching $0.1 \%$ to $0.3 \%$ of the black population, with a tendency to reach an increasingly significant section of the population, due to the high rate of interracial marriage. Its distribution is heterogeneous and more frequent where the rate of Afro-descendants is greater (Northeast). Estimates show more than 2 million hemoglobin $\mathrm{S}(\mathrm{HbS})$ gene carriers in Brazil and more than 8,000 individuals affected by the homozygous form (HbSS). New cases of sickle cell disease range from 700 to 1,000 on a yearly basis, indicating a public health problem in Brazil. . $^{3,45,6,7}$

Among sickle cell diseases, sickle cell anemia has the highest clinical and hematological severity, in addition to the highest prevalence. ${ }^{3}$ Sickle cell anemia is a genetic disease caused by a mutation in the beta-globin gene, originating HbS, which can polymerize and promote red blood cell sickling when in homozygous form (HbSS). ${ }^{4}$ It is characterized by many acute and chronic complications, including anemia, severe infections, hemolytic and vasoocclusive episodes, recurrent pain episodes, stroke, acute chest syndrome, pulmonary hypertension, and chronic organ damage. ${ }^{8,9}$ Additionally, the high risks of infection and splenic sequestration are recognized as preventable causes of mortality and morbidity in young children. ${ }^{9}$

Although sickle cell anemia has been extensively studied in Brazil in terms of population frequency and clinical manifestations, there is still little information on its oral manifestations. Oral manifestations of sickle cell anemia are not pathognomonic of the disease and may be present in individuals with other systemic disorders. ${ }^{10}$ The clinical signs most commonly described in the literature are mucosal pallor, delayed tooth eruption, enamel and dentin mineralization disorders, hypercementosis, pulp calcifications, alterations in the cells of the tongue surface and bone changes, resulting in maxillary protrusion and formation of a thick trabecular pattern. ${ }^{11}$ Maxillary growth and the resulting malocclusion have been associated with bone marrow hyperplasia in these patients ${ }^{12}$ and hypocalcification of the teeth occurs as a consequence of insufficient calcium deposition by ameloblasts and odontoblasts, since the blood supply is impaired in some areas affected by vaso-occlusion. ${ }^{4}$ A study revealed a high prevalence of malocclusion in children and teenagers with sickle cell disease, most of whom had very severe malocclusion. ${ }^{13}$

In addition, patients with sickle cell anemia are more susceptible to infections and to periodontal disease and are at a greater risk for the development of dental caries due to several specific factors to which they are exposed such as high prevalence of dental opacities, frequent and continuous use of drugs containing sucrose, and also frequent intercurrent events and hospitalizations that lead to poor oral hygiene. ${ }^{14,15}$ Preventive measures are important in minimizing the consequences of chronic anemia, sickle cell crises and dental infections, which can trigger these crises. ${ }^{6}$

Therefore, the present research aims to identify the prevalence and severity of developmental defects of enamel (DDE) and to evaluate delayed tooth eruption in children with sickle cell anemia.

\section{Methodology}

This was a cross-sectional study with a census sample of children with sickle cell anemia who sought treatment between September and December 2012 at the Hematology and Hemotherapy Center of Pernambuco (Hemope), a reference center for the treatment of patients with hemoglobin diseases in Recife, in the state of Pernambuco, Brazil, and who met the inclusion criteria. The study population consisted of male and female 56 children aged 6 to 12 years with clinical and laboratory diagnosis of sickle cell anemia established through the newborn screening test.

Only those children subjected to intraoral examination and whose parents and/or guardians signed theinformed consent form for their participation were selected. Children with other systemic diseases, psychiatric disorders, neurological disorders, other special needs and those whose general health status did not allow them to undergo the examination were excluded.

The children were evaluated by a single examiner previously calibrated by a "gold standard" examiner. The inter-examiner calibration consisted of a theoretical 
stage with the presentation of images and the criteria of the DDE index, and a kappa coefficient of 0.75 was obtained. The intra-examiner calibration, which consisted in reassessing one in every eight children after 1 week, resulted in a kappa coefficient of 0.82 . The lingual/palatal, buccal and occlusal/incisal surfaces were evaluated. The kappa values refer to the DDE assessment.

DDE was assessed according to the World Health Organization $(\mathrm{WHO})$ criteria using the modified enamel defects index. ${ }^{16}$ The chronology and sequence of tooth eruption were assessed based on the empty spaces for unerupted teeth, unless the parent or legal guardian reported extractions of any of those teeth, and also based on teeth present when any part of the tooth was visible or could be touched with a dental explorer.

Patient clinical records were used for the clinical examination and notes on the clinical data were made by a collaborator. The dental examination was performed in a dental office after dental prophylaxis, under artificial lighting, with the aid of a mouth mirror, exploratory probes, cotton tweezers and prefabricated cotton rolls for relative isolation.

For data analysis, the patients were divided into three age groups ( 6 to 8 years, $>8$ to 10 years and $>10$ to 12 years) in order to facilitate the comparison of variables. Absolute distributions, univariate and bivariate percentage distributions, and statistical measures were obtained: mean, median and standard deviation. Pearson's chi-square test and McNemar's test were used. The significance level was set at $5 \%$. SPSS (Statistical Package for the Social Sciences), version 17 , was used for entering the data and obtaining the statistical calculations.

This study was approved by the Research Ethics Committee of Hemope (number 028/2010).

\section{Results}

All children examined during the data collection period were selected to participate in the study, as all of them met the inclusion criteria. Thus, the sample comprised 56 children, whose ages ranged from 6 to 12 years, with a mean of 9.32 years, a median of 9.50 years and a standard deviation of 2.02 years. Regarding the distribution of the children by age,
$17(30.4 \%)$ were aged 6 to 8 years, 15 (26.8\%) were aged 8 to 10 years and $24(42.9 \%)$ were aged 10 to 12 years, but the last age group was the most prevalent. In the distribution by sex, male patients were more prevalent (30 children), corresponding to $53.6 \%$ of the total sample.

Of the 56 children analyzed, one had only the deciduous dentition, which was accounted for in the evaluation of delayed tooth eruption but excluded from the evaluation of DDE. Eruption of 828 permanent teeth - most frequently first molars and upper and lower incisors - was observed in the 55 assessed children. Regarding enamel defects, 32 children (58.2\%) presented some defects, whereas 23 (41.8\%) presented no defects.

It was also verified that $87.9 \%$ of erupted permanent teeth presented no defects and $12.1 \%$ presented some type of defect, the most frequent of which were diffuse opacity (6.2\%) and marked opacity (4.5\%). Marked opacity and hypoplasia corresponded to $0.1 \%$, hypoplasia to $0.5 \%$ and marked and diffuse opacities to $0.8 \%$ (Table 1 ).

The presence of enamel defects increased with age, affecting $43.8 \%$ of children aged 6 to 8 years and $66.7 \%$ of those aged 10 to 12 years, but it was similar between sexes. However, there was no significant association between enamel defects and any of the variables $(p>0.05)$ (Table 2$)$.

The occurrence of DDE in the jaws was also evaluated, showing that children with such defects in each dental arch accounted for $40 \%$, without significant difference between the arches. In addition, $21.8 \%(n=12)$ of the children presented defects in both jaws; $18.2 \%(n=10)$ presented defects only in the maxilla; $18.2 \%$ (10) only in the mandible; and $41.8 \%$ ( 23 children) presented no defects in either of the two arches (Table 3).

In this study, delayed tooth eruption was verified in 18 children (32.1\%). Delayed eruption increased with age, affecting $11.8 \%$ of children aged 6 to 8 years, $20.0 \%$ of those aged 8 to 10 years and $54.2 \%$ of those aged 10 to 12 years, demonstrating a significant association between delayed eruption and age $(p<0.05)$. Delayed tooth eruption was higher in males than in females (36.7\% vs. $26.9 \%$ ), but no significant association was found $(\mathrm{p}>0.05)$ (Table 4$)$. 
Enamel defects and tooth eruption disturbances in children with sickle cell anemia

Table 1. Prevalence and distribution of enamel defects in erupted teeth.

\begin{tabular}{|c|c|c|c|c|c|c|c|c|c|c|c|c|c|c|}
\hline \multirow[t]{2}{*}{ Tooth } & \multicolumn{2}{|c|}{ Normal } & \multicolumn{2}{|c|}{ Marked opacity } & \multicolumn{2}{|c|}{ Diffuse opacity } & \multicolumn{2}{|c|}{$\begin{array}{l}\text { Marked opacity } \\
\text { and hypoplasia }\end{array}$} & \multicolumn{2}{|c|}{ Hypoplasia } & \multicolumn{2}{|c|}{$\begin{array}{l}\text { Marked and } \\
\text { diffuse opacity }\end{array}$} & \multicolumn{2}{|c|}{$\begin{array}{c}\text { Total \# of } \\
\text { erupted teeth }\end{array}$} \\
\hline & $n$ & $\%$ & $\mathrm{n}$ & $\%$ & $\mathrm{n}$ & $\%$ & $\mathrm{n}$ & $\%$ & $\mathrm{n}$ & $\%$ & $\mathrm{n}$ & $\%$ & $\mathrm{n}$ & $\%$ \\
\hline 17 & 7 & 87.5 & 1 & 12.5 & - & - & - & - & - & - & - & - & 8 & 100.0 \\
\hline 16 & 51 & 94.4 & - & - & 2 & 3.7 & 1 & 1.9 & - & - & - & - & 54 & 100.0 \\
\hline 15 & 15 & 93.8 & 1 & 6.3 & - & - & - & - & - & - & - & - & 16 & 100.0 \\
\hline 14 & 21 & 91.3 & - & - & 2 & 8.7 & - & - & - & - & - & - & 23 & 100.0 \\
\hline 13 & 12 & 92.3 & - & - & 1 & 7.7 & - & - & - & - & - & - & 13 & 100.0 \\
\hline 12 & 28 & 75.7 & 4 & 10.8 & 3 & 8.1 & - & - & 1 & 2.7 & 1 & 2.7 & 37 & 100.0 \\
\hline 11 & 33 & 75.0 & 2 & 4.5 & 7 & 15.9 & - & - & 1 & 2.3 & 1 & 2.3 & 44 & 100.0 \\
\hline 21 & 37 & 82.2 & 2 & 4.4 & 5 & 11.1 & - & - & - & - & 1 & 2.2 & 45 & 100.0 \\
\hline 22 & 27 & 77.1 & 6 & 17.1 & 2 & 5.7 & - & - & - & - & - & - & 35 & 100.0 \\
\hline 23 & 11 & 100.0 & - & - & - & - & - & - & - & - & - & - & 11 & 100.0 \\
\hline 24 & 23 & 85.2 & 1 & 3.7 & 2 & 7.4 & - & - & - & - & 1 & 3.7 & 27 & 100.0 \\
\hline 25 & 21 & 100.0 & - & - & - & - & - & - & - & - & - & - & 21 & 100.0 \\
\hline 26 & 52 & 94.5 & 1 & 1.8 & 2 & 3.6 & - & - & - & - & - & - & 55 & 100.0 \\
\hline 27 & 7 & 100.0 & - & - & - & - & - & - & - & - & - & - & 7 & 100.0 \\
\hline 47 & 11 & 100.0 & - & - & - & - & - & - & - & - & - & - & 11 & 100.0 \\
\hline 46 & 45 & 84.9 & 3 & 5.7 & 4 & 7.5 & - & - & - & - & 1 & 1.9 & 53 & 100.0 \\
\hline 45 & 14 & 100.0 & - & - & - & - & - & - & - & - & - & - & 14 & 100.0 \\
\hline 44 & 20 & 35.7 & 1 & 1.8 & 2 & 3.6 & & & 1 & 1.8 & 1 & 1.8 & 25 & 100.0 \\
\hline 43 & 21 & 100.0 & - & - & - & - & - & - & - & - & - & - & 21 & 100.0 \\
\hline 42 & 39 & 90.7 & 1 & 2.3 & 3 & 7.0 & - & - & - & - & - & - & 43 & 100.0 \\
\hline 41 & 41 & 83.7 & 3 & 6.1 & 4 & 8.2 & - & - & 1 & 2.0 & - & - & 49 & 100.0 \\
\hline 31 & 44 & 86.3 & 3 & 5.9 & 4 & 7.8 & - & - & - & - & - & - & 51 & 100.0 \\
\hline 32 & 41 & 93.2 & 1 & 2.3 & 2 & 4.5 & - & - & - & - & - & - & 44 & 100.0 \\
\hline 33 & 21 & 95.5 & - & - & 1 & 4.5 & - & - & - & - & - & - & 22 & 100.0 \\
\hline 34 & 21 & 84.0 & 2 & 8.0 & 2 & 8.0 & - & - & - & - & - & - & 25 & 100.0 \\
\hline 35 & 10 & 90.9 & 1 & 9.1 & - & - & - & - & - & - & - & - & 11 & 100.0 \\
\hline 36 & 47 & 87.0 & 3 & 5.6 & 3 & 5.6 & - & - & - & - & 1 & 1.9 & 54 & 100.0 \\
\hline 37 & 8 & 88.9 & 1 & 11.1 & - & - & - & - & - & - & - & - & 9 & 100.0 \\
\hline Total & 728 & 87.9 & 37 & 4.5 & 51 & 6.2 & 1 & 0.1 & 4 & 0.5 & 7 & 0.8 & 828 & 100.0 \\
\hline
\end{tabular}

Table 2. Prevalence of enamel defects according to age and sex.

\begin{tabular}{|c|c|c|c|c|c|c|c|}
\hline \multirow{3}{*}{ Variable } & \multicolumn{6}{|c|}{ Prevalence of enamel defects } & \multirow{3}{*}{$p$-value* } \\
\hline & \multicolumn{2}{|c|}{ Yes } & \multicolumn{2}{|c|}{ No } & \multicolumn{2}{|c|}{ Total } & \\
\hline & $\mathrm{n}$ & $\%$ & $\mathrm{n}$ & $\%$ & $\mathrm{n}$ & $\%$ & \\
\hline \multicolumn{8}{|l|}{ Age (in years) } \\
\hline 6 to 8 & 7 & 43.8 & 9 & 56.3 & 16 & 100.0 & 0.350 \\
\hline$>8$ to 10 & 9 & 60.0 & 6 & 40.0 & 15 & 100.0 & \\
\hline$>10$ to 12 & 16 & 66.7 & 8 & 33.3 & 24 & 100.0 & \\
\hline \multicolumn{8}{|l|}{ Sex } \\
\hline Male & 17 & 58.6 & 12 & 41.4 & 29 & 100.0 & 0.944 \\
\hline Female & 15 & 57.7 & 11 & 42.3 & 26 & 100.0 & \\
\hline Total & 32 & 58.2 & 23 & 41.8 & 55 & 100.0 & \\
\hline
\end{tabular}

*Pearson's chi-square test.
Table 3. Prevalence of enamel defects between the jaws and dental arch.

\begin{tabular}{|c|c|c|c|c|c|c|c|}
\hline \multirow{3}{*}{ Maxilla } & \multicolumn{6}{|c|}{ Mandible } & \multirow{3}{*}{ p-value* } \\
\hline & \multicolumn{2}{|c|}{ Yes } & \multicolumn{2}{|c|}{ No } & \multicolumn{2}{|c|}{ Total } & \\
\hline & $n$ & $\%$ & $n$ & $\%$ & $n$ & $\%$ & \\
\hline Yes & 12 & 21.8 & 10 & 18.2 & 22 & 40.0 & \\
\hline No & 10 & 18.2 & 23 & 41.8 & 33 & 60.0 & 1.000 \\
\hline Total & 22 & 40.0 & 33 & 60.0 & 55 & 100.0 & \\
\hline
\end{tabular}

*McNemar's test. 
Table 4. Prevalence of delayed tooth eruption according to age and sex.

\begin{tabular}{|c|c|c|c|c|c|c|c|}
\hline \multirow{3}{*}{ Variable } & \multicolumn{6}{|c|}{ Prevalence of delayed eruption } & \multirow{3}{*}{ p-value* } \\
\hline & \multicolumn{2}{|c|}{ Yes } & \multicolumn{2}{|c|}{ No } & \multicolumn{2}{|c|}{ Total } & \\
\hline & $n$ & $\%$ & $n$ & $\%$ & $\mathrm{n}$ & $\%$ & \\
\hline \multicolumn{8}{|l|}{ Age (in years) } \\
\hline 6 to 8 & 2 & 11.8 & 15 & 88.2 & 17 & 100.0 & $0.008^{* *}$ \\
\hline$>8$ to 10 & 3 & 20.0 & 12 & 80.0 & 15 & 100.0 & \\
\hline$>10$ to 12 & 13 & 54.2 & 11 & 45.8 & 24 & 100.0 & \\
\hline \multicolumn{8}{|l|}{ Sex } \\
\hline Male & 11 & 36.7 & 19 & 63.3 & 30 & 100.0 & 0.436 \\
\hline Female & 7 & 26.9 & 19 & 73.1 & 26 & 100.0 & \\
\hline Total & 18 & 32.1 & 38 & 67.9 & 56 & 100.0 & \\
\hline
\end{tabular}

"Pearson's chi-square test; ${ }^{* *}$ Significant difference at the $5.0 \%$ level.

Delayed eruption was detected in 38 (2.4\%) of 1,568 teeth. The left lower canines ( 5 cases) and right lower canines ( 7 cases) showed the highest delay frequencies.

\section{Discussion}

In this study, the prevalence of DDE in children with sickle cell anemia aged 6 to 12 years was $58.2 \%$ and the presence of delayed eruption accounted for $32.1 \%$. Soni ${ }^{17}$ in his microradiographic study, described the interruption of the mineralization process in dental tissues of patients with sickle cell anemia, resulting in hypomineralized enamel and dentin. In a document published by the Brazilian Ministry of Health, ${ }^{18}$ hypomaturation and hypomineralization of enamel and dentin, leading to opacities, especially in molars, were associated with sickle cell disease with a prevalence of $67.5 \%$.

A previous study showed that $50 \%$ of sickle cell anemia patients had whitish areas on their teeth, suggesting defects in maturation or hypoplasia of dental tissues. ${ }^{19}$ In another study of patients with sickle cell anemia, the authors found a prevalence of $10 \%$ for generalized hypoplasia and $35 \%$ for hypoplasia of the dental unit. ${ }^{20}$ Clinical alterations consisted of white spots, dark spots and cavitation in the tooth enamel. ${ }^{20}$

There are other chronic diseases described in the literature as possible causes of DDE, such as celiac disease and asthma. The prevalence of DDE in patients with celiac disease was significantly higher
(42.2\%) than in healthy individuals (9.4\%), showing a statistically significant association. ${ }^{21}$ In the study by Ertekin et al., ${ }^{22} 43$ celiac patients (53.1\%) had DDE, showing an association between enamel defects and celiac disease in childhood. In the present study, $58.2 \%$ of children with sickle cell anemia had some type of enamel defect, which was slightly higher than in the aforementioned studies.

In asthmatic patients, the prevalence of DDE was $76.9 \%$, compared to only $26.9 \%$ in the control group..$^{23}$ In the study by Guergolette et al., ${ }^{24} 89.7 \%$ of asthmatic patients had DDE compared to $38.2 \%$ in the control group, and it was then concluded that pediatric patients with asthma are at a greater risk for DDE, thus requiring priority dental care. Compared to asthmatic patients, the present study presented a lower prevalence of DDE.

In the district of Kollam, India, 32.0\% of healthy children had DDE, and the defects were more common in marked opacity. ${ }^{25}$ The prevalence of DDE in Granada, in the Spanish province, was $52.0 \%$, with some form of defect affecting $8.3 \%$ of permanent teeth, among which marked opacity and hypoplasia were the most prevalent and the least prevalent types of DDE, respectively. ${ }^{26}$ On the other hand, a study carried out among children in Romania showed a low prevalence of DDE (9.8\%), with the highest incidence observed for diffuse opacities, followed by marked opacities. ${ }^{27}$ In comparison to these results, the prevalence of DDE in the present study was higher, affecting $58.2 \%$ of the children, with diffuse opacity being the most prevalent defect in permanent teeth $(6.2 \%)$, followed by marked opacity $(4.5 \%)$.

Note that epidemiological studies on the prevalence of DDE exhibit a wide range of variability, which may be explained by the specific characteristics and method adopted in the study such as indices used and the criteria used in the examination..$^{25}$ The prevalence of DDE in permanent teeth is highly variable depending on the types of defects and on the characteristics of the study population. A multitude of etiologic factors and types of pediatric populations, in addition to variable concentrations of fluoride in water, are accountable for this wide variability. ${ }^{27}$ In the 
present study, no patients had access to fluoridated drinking water, since fluorosis needs a differential diagnosis from DDE.

In the present study, delayed tooth eruption was verified in 18 children (32.1\%) and it increased with age, showing a statistically significant association. Other studies aimed at identifying the prevalence of orofacial manifestations in patients with sickle cell anemia observed delayed eruption in both primary and permanent dentition. Franco et al..$^{19}$ observed delayed tooth eruption in $12.5 \%$ of children aged over 9 years. Santo et al. ${ }^{20}$ verified a change in tooth eruption in $14.0 \%$ of children and teenagers with sickle cell anemia. Mendes et al. ${ }^{28}$ detected a significantly higher prevalence of delayed tooth eruption in patients with sickle cell anemia when compared to patients without the disease. On the other hand, Sears et al. ${ }^{29}$ did not find significant differences between the chronological and dental ages of patients with sickle cell anemia, contrasting with the results of the studies mentioned above.

Celiac patients may also present delayed tooth eruption. ${ }^{30}$ The hypothesis for this is that these patients are often subject to weight loss and have less somatic growth compared to healthy individuals. ${ }^{31}$ Delayed tooth eruption was reported in $26.0 \%$ of pediatric patients with celiac disease. ${ }^{32}$ In the present study, the delay in tooth eruption in sickle cell anemia patients was higher (32.1\%). However, the study by Condò et al. ${ }^{31}$ concluded that $70 \%$ of the children with celiac disease presented delayed tooth eruption, which was similar in both sexes. The prevalence of delayed tooth eruption was $3.4 \%{ }^{33}$ in 4,611 healthy Korean children, which was extremely lower when compared to the rate observed in patients with sickle cell disease or celiac disease. However, such comparisons should be interpreted with caution since sample size and methods used to assess delayed tooth eruption varied across studies. Most studies also report that the emergence of permanent teeth occurs earlier in girls than in boys. ${ }^{34,35,36}$ In this study, the delay in dental eruption was also higher in males than in females, but no significant association was found $(p>0.05)$.

The results of this study show that there is a statistically significant association between delayed tooth eruption and age in sickle cell anemia patients, but no statistically significant difference in relation to sickle cell anemia and DDE, according to sex and age. It is important to emphasize that enamel development can be affected by many different environmental and genetic factors. Amelogenesis is a highly regulated process and can be negatively influenced by pathological/medical conditions such as fever, infection, trauma, changes in oxygen saturation, antibiotics, excess fluoride exposure, low birth weight and malnutrition. Thus, children with more frequent and serious illnesses are more likely to have enamel defects. ${ }^{37}$

Therefore, dental surgeons should be trained to treat patients with sickle cell anemia, considering that a delay in dental eruption may have an impact on the development of dental occlusion and DDE may have a significant clinical impact on aesthetics, tooth sensitivity, tooth wear and dentofacial anomalies. The abnormal structure and morphology of the affected teeth may trigger the onset and progression of dental caries, ${ }^{38}$ a disease with a high prevalence in children with sickle cell disease ${ }^{39}$ Oral complications in this population can cause bacterial infections and bring about vaso-occlusive crises, compromising the quality of life of sickle cell disease patients. ${ }^{18} \mathrm{So}$, it is important that all clinicians be aware of the pathophysiology and oral manifestations of sickle cell anemia and that dental surgeons carefully obtain the patient's clinical history and information about particular features in order to plan a dental treatment that suits the patient's limitations and needs. ${ }^{40}$

The data obtained in the present study should be interpreted with caution due to limitations such as: a. sample size, as 116 children with sickle cell disease sought treatment at HEMOPE in 2012 (average of 9.7 children seen per month), and the sample of the present study comprised almost half of all those patients ( 56 children); and b. type of study, since the children were analyzed only at a certain time and were not followed up to evaluate the presence of DDE and the chronology of eruption of the subsequent teeth. Moreover, oral manifestations in sickle cell disease patients are not 
disease-specific, so other etiologic factors, including systemic, local and environmental conditions, can occur concomitantly with sickle cell anemia and influence the analyzed variables. Despite these limitations, this study offers relevant perspectives for the scientific community.

Finally, since there are few studies on oral manifestations in patients with sickle cell anemia, it is suggested that more research be conducted. Also, it would be relevant to evaluate whether DDE and delayed tooth eruption are caused by sickle cell anemia or have other causes in order to verify if this disease may be an etiologic factor for these oral manifestations.

\section{References}

1. Modell B, Darlison M. Global epidemiology of haemoglobin disorders and derived service indicators. Bull World Health Organ. 2008 Jun;86(6):480-7. https://doi.org/10.2471/BLT.06.036673

2. Dahmani F, Benkirane S, Kouzih J, Woumki A, Mamad H, Masrar A. [Epidemiological profile of hemoglobinopathies: a cross-sectional and descriptive index case study]. Pan Afr Med J. 2017 Jun;27:150. French. https://doi.org/10.11604/pamj.2017.27.150.11477

3. Naoum PC. [Erythrocytes and environmental interferences on sickle cell anaemia]. Rev Bras Hematol Hemoter. 2000 Apr;22(1):5-22. Portuguese. https://doi.org/10.1590/S1516-84842000000100003

4. Botelho DS, Vergne AA, Bittencourt S, Ribeiro ED. Perfil sistêmico e conduta odontológica em pacientes com anemia falciforme. Int J Dent. 2009 Jan-Mar;8(1):28-35.

5. Ministério da Saúde (BR). Manual de diagnóstico e tratamento de doenças falciformes. Brasília, DF: Anvisa; 2002.

6. Ministério da Saúde (BR). Secretaria de Atenção à Saúde. Manual de saúde bucal na doença falciforme. Brasilia, DF: Ministério da Saúde; 2005.

7. Cançado RD, Jesus JA. A. [Sickle cell disease in Brazil]. Rev Bras Hematol Hemoter. 2007;29(3):203-6. Portuguese. https://doi.org/10.1590/S1516-84842007000300002

8. Steinberg MH. Genetic etiologies for phenotypic diversity in sickle cell anemia. Sci World J. 2009 Jan;9:46-67. https://doi.org/10.1100/tsw.2009.10

9. Therrell BL Jr, Lloyd-Puryear MA, Eckman JR, Mann MY. Newborn screening for sickle cell diseases in the United States: A review of data spanning 2

\section{Conclusions}

DDE had a high prevalence, increased with age and was similar between sexes. Most of the analyzed children had some type of enamel defect, and diffuse opacity was found to be the most prevalent one. Delayed eruption was higher in males and showed a significant association with age.

\section{Acknowledgements}

We would like to thank the Hematology and Hemotherapy Center of Pernambuco, which made this study possible, and the National Council for Scientific and Technological Development for the financial support.

decades. Semin Perinatol. 2015 Apr;39(3):238-51.

https://doi.org/10.1053/i.semperi.2015.03.008

10. Fonseca M, Oueis HS, Casamassimo PS. Sickle cell anemia: a review for the pediatric dentist. Pediatr Dent. 2007 Mar-

Apr;29(2):159-69.

11. Pithon MM. Orthodontic treatment in a patient with sickle cell anemia. Am J Orthod Dentofacial Orthop. 2011 Nov;140(5):713-9. https://doi.org/10.1016/j.ajodo.2010.02.039

12. Javed F, Correa FO, Nooh N, Almas K, Romanos GE, Al-Hezaimi K. Orofacial manifestations in patients with sickle cell disease. Am J Med Sci. 2013 Mar;345(3):234-7. https://doi.org/10.1097/MAJ.0b013e318265bl46

13. Luna ACA, Godoy F, Menezes VA. Malocclusion and treatment need in children and adolescents with sickle cell disease. Angle Orthod. 2014 May;84(3):467-72. https://doi.org/10.2319/070913-503.1

14. Crawford JM. Periodontal disease in sickle cell disease subjects. J Periodontol. 1988 Mar;59(3):164-9. https://doi.org/10.1902/jop.1988.59.3.164

15. Taylor LB, Nowak AJ, Giller RH, Casamassimo PS. Sickle cell anemia: a review of the dental concerns and a retrospective study of dental and bony changes. Spec Care Dentist. 1995 Jan-Feb;15(1):38-42. https://doi.org/10.1111/j.1754-4505.1995.tb00469.x

16. World Health Organization. Oral health surveys: basic methods. 4th ed. Geneve: World Health Organization; 1997.

17. Soni NN. Microradiographic study of dental tissues in sickle-cell anaemia. Arch Oral Biol. 1966 Jun;11(6):561-4. https://doi.org/10.1016/0003-9969(66)90221-4 
Enamel defects and tooth eruption disturbances in children with sickle cell anemia

18. Ministério da Saúde (BR). Secretaria de Atenção à Saúde. Manual de saúde bucal na doença falciforme. Brasilia, DF: Ministério da Saúde; 2007.

19. Franco BM. Gonçalves JCH, Santos CRR. Manifestações bucais da anemia falciforme e suas implicações no atendimento odontológico. Arq Odontol. 2007;43(3):92-6.

20. Santo DD, Gabardo G, Albini M, Melo NS, Lima AA. Incidência das principais manifestações bucais em crianças e adolescentes com anemia falciforme. Dens. 2009 Nov-Apr;17(2). https://doi.org/10.5380/rd.v17i2.15558

21. Avşar A, Kalayci AG. The presence and distribution of dental enamel defects and caries in children with celiac disease. Turk J Pediatr. 2008 Jan-Feb;50(1):45-50.

22. Ertekin V, Sumbullu MA, Tosun MS, Selimoglu MA, Kara M, Kilic N. Oral findings in children with celiac disease. Turk J Med Sci. 2012;42(4):613-7.

23. Visweswar VK, Amarlal D, Veerabahu R. Prevalence of developmental defects of enamel in children and adolescents with asthma: a cross-sectional study. Indian J Dent Res. 2012 SepOct;23(5):697-8. https://doi.org/10.4103/0970-9290.107432

24. Guergolette RP, Dezan CC, Frossard WT, Ferreira FB, Cerci Neto A, Fernandes KB. Prevalence of developmental defects of enamel in children and adolescents with asthma. J Bras Pneumol. 2009 Apr;35(4):295-300. https://doi.org/10.1590/S1806-37132009000400002

25. Ravindran R, Saji AM. Prevalence of the developmental defects of the enamel in children aged 12-15 years in Kollam district. J Int Soc Prev Community Dent. 2016 JanFeb;6(1):28-33. https://doi.org/10.4103/2231-0762.175407

26. Robles MJ, Ruiz M, Bravo-Perez M, González E, Peñalver MA. Prevalence of enamel defects in primary and permanent teeth in a group of schoolchildren from Granada (Spain). Med Oral Patol Oral Cir Bucal. 2013 Mar;18(2):e187-93. https://doi.org/10.4317/medoral.18580

27. Mihaela M, Pasareanu M, Maxim A. Etiological factors of enamel developmental defects of permanent teeth in children and adolescent. Romanian J Oral Rehabil. 2011;3:72-8.

28. Mendes PH, Fonseca NG, Martelli DR, Bonan PR, Almeida LK, Melo LA et al. Orofacial manifestations in patients with sickle cell anemia. Quintessence Int. 2011 Sep;42(8):701-9.

29. Sears RS, Nazif MM, Zullo T. The effects of sickle-cell disease on dental and skeletal maturation. ASDC J Dent Child. 1981 Jul-Aug;48(4):275-7.
30. Macho VM, Coelho AS, Silva DMV, Andrade DJ. Oral manifestations in pediatric patients with coeliac disease: a review article. Open Dent J. 2017 Oct;11(1):539-45. https://doi.org/10.2174/1874210601711010539

31. Condò R, Costacurta M, Maturo P, Docimo R. The dental age in the child with coeliac disease. Eur J Paediatr Dent. 2011 Sep;12(3):184-8.

32. Campisi G, Di Liberto C, lacono G, Compilato D, Di Prima L, Calvino $\mathrm{F}$ et al. Oral pathology in untreated coeliac [corrected] disease. Aliment Pharmacol Ther. 2007 Dec;26(11-12):152936. https://doi.org/10.1111/j.1365-2036.2007.03535.x

33. Park MK, Shin MK, Kim SO, Lee HS, Lee JH, Jung $\mathrm{HS}$ et al. Prevalence of delayed tooth development and its relation to tooth agenesis in Korean children. Arch Oral Biol. 2017 Jan;73:243-7. https://doi.org/10.1016/i.archoralbio.2016.10.024

34. Diamanti J, Townsend GC. New standards for permanent tooth emergence in Australian children. Aust Dent J. 2003 Mar;48(1):39-42. https://doi.org/10.1111/i.1834-7819.2003.tb00007.x

35. Oziegbe EO, Esan TA, Oyedele TA. Brief communication: emergence chronology of permanent teeth in Nigerian children. Am J Phys Anthropol. 2014 Mar;153(3):506-11. https://doi.org/10.1002/ajpa.22447

36. Eskeli R, Lösönen M, Ikävalko T, Myllykangas R, Lakka T, Laine-Alava MT. Secular trends affect timing of emergence of permanent teeth. Angle Orthod. 2016 Jan;86(1):53-8. https://doi.org/10.2319/121014-894.1

37. Lacruz RS, Habelitz S, Wright JT, Paine ML. Dental enamel formation and implications for oral health and disease. Physiol Rev. 2017 Jul;97(3):939-93. https://doi.org/10.1152/physrev.00030.2016

38. Farsi N. Developmental enamel defects and their association with dental caries in preschoolers in Jeddah, Saudi Arabia. Oral Health Prev Dent. 2010;8(1):85-92.

39. Luna AC, Rodrigues MJ, Menezes VA, Marques KM, Santos FA. Caries prevalence and socioeconomic factors in children with sickle cell anemia. Braz Oral Res. 2012 Jan-Feb;26(1):43-9. https://doi.org/10.1590/S1806-83242012000100008

40. Acharya S. Oral and dental considerations in management of sickle cell anemia. Int J Clin Pediatr Dent. 2015 MayAug;8(2):141-4. https://doi.org/10.5005/ip-journals-10005-1301 